\title{
$\mathrm{PH} 105_{\text {deate }}$
}

Interpretación y gestión del patrimonio en los espacios del turismo oscuro

coordinan Óscar Navajas Corral y Maribel Rodríguez Achútegui

\section{Uso y abuso del turismo oscuro como paradigma. ¿Un concepto saturado?}

David González Vázquez | Observatorio Europeo de Memorias, Universitat de Barcelona

URL de la contribución <www.iaph.es/revistaph/index.php/revistaph/article/view/5033>

Pocas modalidades de turismo han recibido tanta atención en las últimas dos décadas como el llamado turismo oscuro, una categoría asociada genéricamente a la práctica turística en lugares relacionados con la muerte, la tragedia y lo macabro. Una atención promovida desde la esfera académica cuya proyección ha convertido al turismo oscuro, también, en un claro protagonista de los focos mediáticos. Literatura, prensa, teatro, televisión y plataformas digitales de entretenimiento han sido participes de la consolidación de un fenómeno que sobrepasa, como decíamos, el ámbito académico.

Semejante impacto e implantación pueden suponer un problema a la hora de establecer los límites conceptuales de un modelo cuya idiosincrasia le permite ser aplicado en una infinidad de casos concretos. Desde una recreación kitsch a la experiencia educativa en un anti-

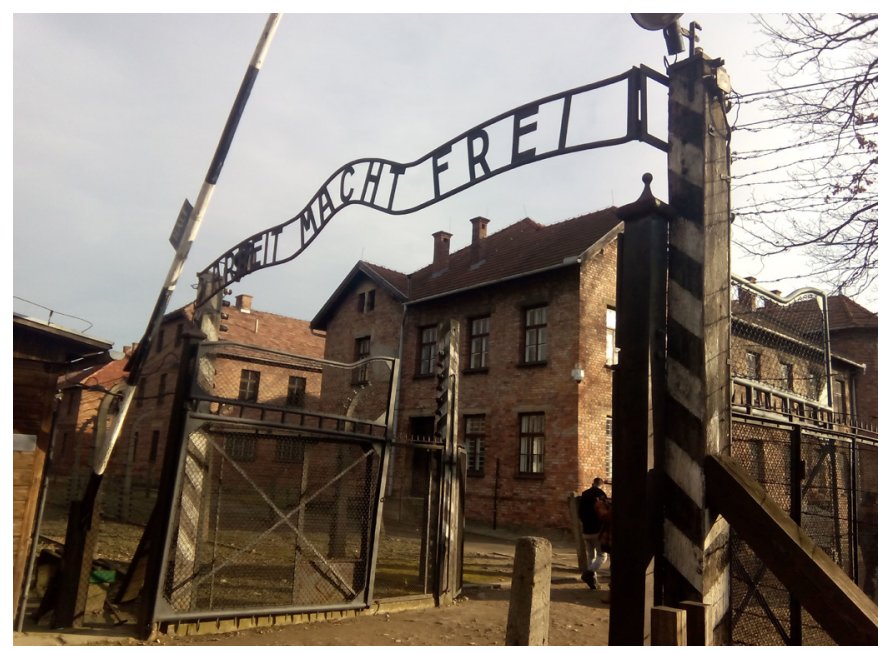

Entrada al Museo Memorial de Auschwitz-Birkenau, 2017 | foto todas las imágenes que ilustran esta contribución son de David González Vázquez guo campo de concentración, todo es susceptible de ser analizado bajo el paradigma del turismo oscuro. Así lo plasmaba, de hecho, Phillip Stone (2006) en su arcaico y sobreexplotado Dark tourism Spectrum. Otros autores de referencia, como Sharpley $(2009,6)$, apuntan que "the meaning of the term has become increasingly diluted and fuzzy", mientras que algunas de las últimas investigaciones ponen el foco en la complejidad conceptual del fenómeno. Así, Light (2017) y González Vázquez (2018) han concluido en reconocer al turismo oscuro como una suerte de categoría paraguas donde todo cabe, siempre y cuando tenga una mínima vinculación con sus elementos definitorios básicos, lo cual conlleva una enorme dificultad a la hora de establecer los límites estructurales del fenómeno.

Una complejidad a la hora de identificar unas determinadas prácticas con uno u otro modelo que surge ya en los inicios de la propia conceptualización del turismo oscuro, tarea que corrió a cargo de los académicos británicos Malcolm Foley y John Lennon a mediados de los años 90 del siglo XX. Así, en un número monográfico de la revista International Journal of Heritage Studies, presentaron oficialmente el concepto de Dark Tourism (Foley y Lennon, 1996a, 1996b), a la par que, el también británico, Anthony Seaton hacía lo propio con el concepto cuyo vocablo español es conocido como tanatoturismo -Thanatourism- (Seaton 1996). Pese a que el espectro analítico de ambas modalidades es similar, se distingue a Thanatourism de Dark Tourism en que la primera aplica en casos única y exclusivamente relacionados con la muerte, mientras que la segunda abarca prácticas más genéricas vinculadas a la tragedia. Aunque en principio pueda parecer una diferencia notable, ha existido siempre cierta confusión entre ambos conceptos y 


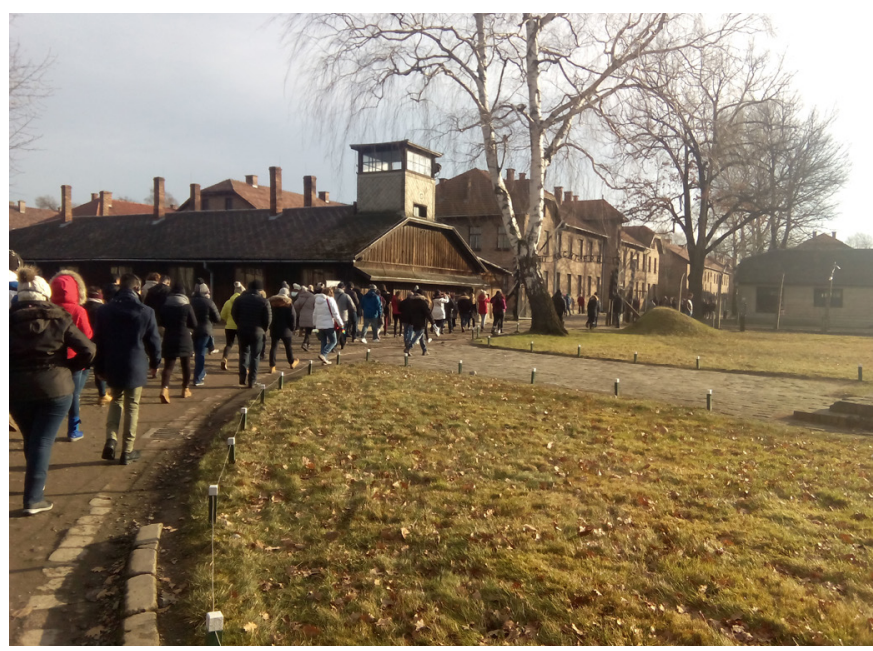

Museo Memorial de Auschwitz-Birkenau

han sido utilizados generalmente de manera indistinta. A tal respecto, no es extraño que Philip Stone $(2013,310)$ defina al tanatoturismo como un "scholarly sister term" del turismo oscuro.

En cualquier caso, al tratarse de un concepto plenamente impuesto desde la esfera académica, y, por tanto, ajeno a ninguna estrategia de difusión proveniente de la propia oferta turística, resulta realmente complicado encontrar sites turísticos cuya relación con el turismo oscuro provenga desde la propia imagen que la gestión del site quiera proyectar de sí mismo. En otras palabras, la oferta turística no se siente identificada con el turismo oscuro (Wight 2009; Baldwin y Sharpley 2009; Magee y Gilmore, 2015; Seaton et ál. 2015). ¿Y la demanda? ¿Son los turistas conscientes de estar practicando turismo oscuro? Ello podrá suceder en mayor o menor medida en función de la imagen percibida del turismo oscuro y del tipo de motivación de cada visitante específico, aunque, como afirman numerosos autores (Slade 2003; Baldwin y Sharpley 2009; Biran et ál. 2011; Isaac y Ashworth 2012), es evidente que no todos los visitantes de lugares dark son turistas dark. Puede afirmarse, incluso, que una buena mayoría de visitantes a determinados lugares vinculados con la idea del turismo oscuro quedarían totalmente horrorizados al saberse clasificados junto a aquellos que visitan otros lugares oscuros de carácter más banal o superficial (Stone 2006; Baldwin y Sharpley 2009; Roberts y Stone 2014).

Así, se identifica una clara divergencia entre los análisis del mundo académico y la realidad turística practicada sobre el terreno. Una divergencia que, como decíamos, no sólo se aplica en este caso, sino que puede detectarse también a la hora de establecer una correcta categorización de aquellas prácticas turísticas que de alguna manera encajan en la definición genérica del turismo oscuro. La problemática que aquí trasciende, pues, apunta a si realmente resulta utilitario el uso del concepto de Dark Tourism para analizar casos específicos de la complejidad, por ejemplo, del Holocausto y otros genocidios. O incluso, más allá de posibles debates éticos, si englobar a toda esa infinidad de prácticas dentro de un modelo tan genérico resulta lo adecuado para el avance científico.

Una vez transcurridos 25 años desde la implantación del concepto de turismo oscuro en la esfera académica, y tras decenas de aportaciones relevantes realizadas por diversos autores al respecto de la idiosincrasia misma del turismo oscuro, habrá que observar atentamente las líneas de investigación propuestas para los años venideros. Veremos si el turismo oscuro como paradigma analítico es y sigue siendo útil o, por el contrario, puede llegar a confirmarse una sobresaturación que acabe descartando su uso en favor de otros paradigmas más específicos.

\section{BIBLIOGRAFÍA}

- Baldwin, F. y Sharpley, R. (2009) Battlefield Tourism: Bringing Organised Violence Back to Life. En: Sharpley, R. y Stone, P. (ed.) (2009) The Darker Side of Travel. The Theory and Practice of Dark Tourism. Bristol: Channel View Publications, pp. 186-206

- Biran, A., Poria, Y. y Oren, G. (2011) Sought experiences at (dark) heritage sites. Annals of tourism Research, vol. 38, n. ${ }^{\circ}$ 3, pp. 820-841

- Foley, M. y Lennon, J. (1996a) Editorial: Heart of Darkness. International Journal of Heritage Studies, vol. 2, n. ${ }^{\circ} 4$, pp. 195-197 
- Foley, M. y Lennon, J. (1996b) JFK and Dark Tourism: a fascination with assassination. International Journal of Heritage Studies, vol. 2, n. ${ }^{\circ} 4$, pp. 198-211

- González Vázquez, D. (2018) Dark tourism and memorial tourism: Nexus and divergences between theoretical models. European Journal of Tourism Research, n. ${ }^{\circ} 20$, pp. 46-58

- Isaac, R.K. y Ashworth, G. (2012) Moving from pilgrimage to "Dark" Tourism: Leveraging tourism in Palestine. Tourism, Culture and Communication, n. ${ }^{\circ} 11$, pp. 149-164

- Light, D. (2017) Progress in dark tourism and thanatourism research: An uneasy relationship with heritage tourism. Tourism management, n. ${ }^{\circ} 61$, pp. 275-301

- Magee, R. y Gilmore, A. (2015) Heritage site management: from dark tourism to transformative service experience? The Service Industries Journal, vol. 35, n. ${ }^{\circ}$ 15-16, pp. 898-917

- Roberts, C., y Stone, P. (2014) Dark Tourism and Dark Heritage: Emergent Themes, Issues and Consequences. En: Convery, I., Corsane, G., y Davids, P. (ed.) (2014) Displaced Heritage. Responses to disaster, trauma, and loss. Newcastle: The Interpretation Centre for Cultural and Heritage Studies (Newcastle University), pp. 9-18

- Seaton, A.V. (1996) Guided by the dark: from thanatopsis to thanatourism. International Journal of Heritage Studies, vol. 2, n. ${ }^{\circ} 4$, pp. $234-244$

- Seaton, A., North, M. y Gajda, G. (2015) Last Resting Places? Recreational Spaces or Thanatourism Attractions the Future of Historic Cemeteries and Churchyards in Europe. En: Gammon, S. y Elkington, S. (ed.) Landscapes of leisure: Space, Place and Identities. Basingstoke: Palgrave, pp. 71-95

- Sharpley, R. (2009) Shedding Light on Dark Tourism: An Introduction. En: Sharpley, R. y Stone, P. (ed.) The Darker Side of Travel. The Theory and Practice of Dark Tourism. Bristol: Channel View Publications, pp. 3-22

- Slade, P. (2003) Gallipoli Thanatourism: The meaning of ANZAC. Annals of tourism research, vol. 30, n. ${ }^{\circ} 4$, pp. 779-794

- Stone, P. (2006) A dark tourism spectrum: Towards a typology of death and macabre related tourist sites, attractions and exhibitions. Tourism: an Interdisciplinary International Journal, vol. 52, n. ${ }^{\circ} 2$, pp. $145-160$

- Stone, P. (2013) Dark Tourism Scholarship: a critical review. International Journal of Culture, Tourism and Hospitality Research, vol. 7, n. ${ }^{\circ}$ 3, pp. 307-318

- Wight, C. (2009) Contested National Tragedies: An Ethical Dimension. En: Sharpley, R. y Stone, P. (ed.) The Darker Side of Travel. The Theory and Practice of Dark Tourism. Bristol: Channel View Publications, pp. 129-144 